\title{
Male Partners' Involvement in the Prevention of Mother-to-Child Transmission of HIV and Associated Factors in Arba Minch Town and Arba Minch Zuria Woreda, Southern Ethiopia
}

\author{
Marelign Tilahun $^{1}$ and Shikur Mohamed ${ }^{2}$ \\ ${ }^{1}$ Social and Public Health Unit, College of Health Sciences, Debre Tabor University, P.O. Box 272, Debre Tabor, Ethiopia \\ ${ }^{2}$ Department of Public Health, College of Medicine and Health Sciences, Arba Minch University, P.O. Box 21, Arba Minch, Ethiopia
}

Correspondence should be addressed to Marelign Tilahun; marikum74@gmail.com

Received 3 February 2015; Revised 27 April 2015; Accepted 24 May 2015

Academic Editor: Beatriz Gonzalez López-Valcárcel

Copyright (C) 2015 M. Tilahun and S. Mohamed. This is an open access article distributed under the Creative Commons Attribution License, which permits unrestricted use, distribution, and reproduction in any medium, provided the original work is properly cited.

Background. Male involvement is an important determinant of prevention of mother-to-child transmission of HIV. However, male involvement in prevention of mother-to-child transmission of HIV in Ethiopia is not well known. Objectives. To assess male partners involvement in prevention of mother-to-child transmission of HIV and associated factors in Arba Minch town and Arba Minch Zuria woreda. Methods. Community based study was conducted in Arba Minch town and Arba Minch Zuria district. Multistage sampling technique was used and data were collected using interviewer administered standard questionnaire. Multiple logistic regression analysis was used to determine the presence of statistically significant associations between the outcome variable and the independent variables. Results. The level of male involvement in PMTCT program in Arba Minch town and Zuria district was 53\%. Several factors appear to contribute to male involvement in the PMTCT program including age, residence, education level, knowledge on HIV, knowledge on PMTCT, accessibility of health facility, having weak perception for male involvement in PMTCT, having perception of ANC attendance being females' responsibility, ever use of khat, and ever use of cigarette. Conclusion. Geographical accessibility of health facility and male's knowledge on PMTCT should be improved to increase their involvement in PMTCT.

\section{Introduction}

Mother-to-child HIV transmission of HIV remains a significant problem in the developing world despite the development and growing availability of effective prevention methods appropriate for resource-limited settings [1,2]. Male partners play a role not only in women's risk of acquiring HIV but also in terms of her utilization of the PMTCT program: for the mother to test for HIV, for the mother to return for the result, for the couple to use condoms, for the mother to receive medication, and for her to follow the infant feeding advice given $[1,3-6]$. In a previous study, it is observed that the involvement of male partners in antenatal VCT was associated with increased uptake of interventions to prevent vertical and sexual HIV transmission [4].
From other sub-Saharan African studies, the fear of a partner's negative reaction towards the mother testing for HIV and fear of disclosure of the test results have been found to be barriers to HIV testing for pregnant women in the PMTCT program $[5,7]$. Other studies from subSaharan Africa found that couple HIV counseling appeared to improve the acceptability of HIV testing and uptake of ARV prophylaxis for PMTCT. Women who received couple counseling did not report an increased risk of adverse social events compared to individually counseled women [8-10]. Dropout among those who have discussed HIV testing with their partners was found to be low in Burkina Faso [11].

Studies in Kenya found that women accompanied by their partner for HIV testing were three times more likely to return for antiretroviral prophylaxis. Couple posttest counseling was 
also associated with an eightfold increase in postpartum follow-up, as well as greater antiretroviral utilization and formula feeding $[4,9]$. In Uganda male involvement is associated with increased uptake of HIV testing and preventive interventions for vertical and sexual transmissions of HIV [12].

Male involvement is an important determinant factor of PMTCT service uptake. However no study was conducted on involvement of male partners in PMTCT programs in Ethiopia and particularly in the present study area. Therefore, this study was conducted to identify the determinant factors of male partner's involvement in the PMTCT program in Arba Minch town and Arba Minch Zuria district.

\section{Methods}

2.1. Study Design and Study Area. Community based study was conducted from February 2013 to September 2013. The study was conducted in Arba Minch town and Arba Minch Zuria district which is located about $505 \mathrm{~km}$ south of Addis Ababa, the capital of Ethiopia. There are three hospitals and sixty-eight health centers in Gamo-Gofa zone offering health care services for the total population.

2.2. Study Population. The study population was all male partners of reproductive age women (15-49 years) who give birth during the previous one year in Arba Minch town and Arba Minch Zuria woreda.

2.3. Sample Size Determination Method. Sample size of 720 was determined by the formula of two population proportion estimations using software Epi-info stat calc. with 95\% confidence interval, power of $80 \%$, odds ratio of 2.0 , an estimated $26 \%$ male partners involvement in PMTCT [10], rural to urban ratio of $2: 1$, and a conservative design effect of 2.0 to accommodate for intracluster variability.

2.4. Sampling Procedure. Multistage sampling technique was used. There are 11 Kebeles in Arba Minch town and 29 Kebeles in Arba Minch Zuria woreda out of which three Kebeles in Arba Minch town and six Kebeles in Arba Minch Zuria woreda were selected by simple random sampling. Individual Kebele households having children who are less than one year were then selected using a systematic sampling technique.

\subsection{Operational Definitions}

Male Involvement in PMTCT. The level of male involvement in PMTCT was determined using the following six variables which were taken from previous literature [13]:

(1) Did you know your wife's appointment for ANC the last time she was pregnant?

(2) Did you discuss with your wife counseling and testing for HIV the last time she was pregnant?

(3) Have you ever gone together with your wife to an ANC/PMTCT clinic?
(4) Have you ever counselled and tested for HIV together with your wife at an ANC/PMTCT clinic?

(5) Did you support your wife's antenatal visits financially?

(6) Do you accept if health professionals inform you to use condom during the time of your wife's pregnancy?

The involvement score for each respondent could range from $0=$ no involvement to $6=$ involved in all 6 activities. A total score of 4-6 was considered as "involved in PMTCT" and 0-3 as "not involved in PMTCT" relative to this particular population and this score of measuring PMTCT involvement was taken from previous literature [13].

2.6. Data Collection and Quality Control. Data were collected using interviewer administered standard questionnaire. Individuals who have completed grade 12 were recruited as data collectors and were trained on the data collection procedures. Male involvement in PMTCT was considered as the outcome or dependent variable, while sociodemographic variables (age, residence, religion, ethnicity, income, occupation, and education level), residence, number of children, cohabitation duration, alcohol use, khat use, cigarette smoking, comprehensive knowledge on HIV/AIDS, perceived risk of HIV, knowledge on MTCT of HIV, knowledge on PMTCT of HIV, knowledge of services given at ANC clinic, and accessibility of health services were considered as independent variables.

2.7. Data Processing and Analysis. All returned questionnaires were checked for completeness and consistency of responses. After cleaning, data was coded and entered into and analyzed using SPSS for Windows version 20.0. Descriptive statistics such as frequencies, proportion, and cross tabulations were used to describe the study population in relation to relevant variables. Multiple logistic regression analysis was used to determine the strength of associations between the outcome variable and the independent variables.

2.8. Ethical Consideration. Ethical clearance was obtained from ethical review committee of Arba Minch University and permission was obtained from the respective Kebeles in Arba Minch town and Arba Minch Zuria woreda. Verbal informed consent from each study participant was obtained after clear explanation about the purpose of the study.

\section{Results}

3.1. Sociodemographic Characteristics. Of the 700 respondents included in the analysis, 382 (54.6\%) were in the 26-35 age group. The mean age was 31 years with standard deviation (SD) of 6.57 years. Sixty-five percent of the participants were rural, while the rest were urban. According to the study participants score on the six questions used to measure the level of male involvement PMTCT 53\% of them were found to be involved by having a score of $4-6$ out of the six questions (Table 1). 
TABLE 1: Sociodemographic characteristics of the study participants in Arba Minch town and Zuria woreda southern Ethiopia, 2014.

\begin{tabular}{|c|c|c|c|}
\hline \multirow{2}{*}{ Variables } & \multicolumn{2}{|c|}{ Involved in PMTCT } & \multirow{2}{*}{ Total: $n(\%)$} \\
\hline & Yes: $n(\%)$ & No: $n(\%)$ & \\
\hline \multicolumn{4}{|c|}{ Age $[$ mean $( \pm S D)=30.77( \pm 6.57)]$} \\
\hline $17-25$ & $79(11.3)$ & $89(12.7)$ & $168(24.0)$ \\
\hline $26-35$ & $225(32.1)$ & $157(22.4)$ & $382(54.6)$ \\
\hline $36-55$ & $67(9.6)$ & $83(11.9)$ & $150(21.4)$ \\
\hline \multicolumn{4}{|l|}{ Residence } \\
\hline Urban & $168(24.0)$ & $75(10.7)$ & $243(34.7)$ \\
\hline Rural & $203(29.0)$ & $254(36.3)$ & $457(65.3)$ \\
\hline \multicolumn{4}{|l|}{ Ethnic group } \\
\hline Gamo & $277(39.6)$ & $270(38.6)$ & $547(78.1)$ \\
\hline Gofa & $9(1.3)$ & $10(1.4)$ & $19(2.7)$ \\
\hline Wolayta & $45(6.4)$ & $41(5.9)$ & $86(12.3)$ \\
\hline Amhara & $16(2.3)$ & $4(0.6)$ & $20(2.9)$ \\
\hline Others* & $24(3.4)$ & $4(0.6)$ & $28(4.0)$ \\
\hline \multicolumn{4}{|l|}{ Religion } \\
\hline Orthodox Christian & $128(18.3)$ & $93(13.3)$ & $221(31.6)$ \\
\hline Muslim & $18(2.6)$ & $7(1.0)$ & $25(3.6)$ \\
\hline Protestant & $223(31.9)$ & $217(31.0)$ & $440(62.9)$ \\
\hline Others** & $2(0.3)$ & $12(1.7)$ & $14(2.0)$ \\
\hline \multicolumn{4}{|l|}{ Education } \\
\hline No education & $27(3.9)$ & $90(12.9)$ & $117(16.4)$ \\
\hline Primary education & $172(24.6)$ & $152(21.8)$ & $324(46.3)$ \\
\hline Secondary \& above & $172(24.6)$ & $87(12.4)$ & $259(37.0)$ \\
\hline \multicolumn{4}{|l|}{ Occupation } \\
\hline Government employed & $42(6.0)$ & $16(2.3)$ & $58(8.3)$ \\
\hline Merchant & $60(8.6)$ & $33(4.7)$ & $93(13.3)$ \\
\hline Daily laborer & $124(17.7)$ & $120(17.1)$ & $244(34.9)$ \\
\hline Farmer & $92(13.1)$ & $116(16.6)$ & $208(29.7)$ \\
\hline Student & $53(7.6)$ & $44(6.3)$ & $97(13.9)$ \\
\hline \multicolumn{4}{|l|}{ Monthly income } \\
\hline$\leq 300$ birr & $124(17.7)$ & $163(23.3)$ & $287(41.1)$ \\
\hline 301-725 birr & $130(18.6)$ & $109(15.6)$ & $239(34.2)$ \\
\hline$\geq 726$ birr & $116(16.6)$ & $57(8.2)$ & $173(24.7)$ \\
\hline
\end{tabular}

${ }^{*}$ Wolayta, Konso, Gurage, and Oromo; ${ }^{* *}$ Catholic, Adventist, only Jesus.

3.2. Level of Male Involvement in PMTCT Program. The level of male involvement in PMTCT was assessed using the variables shown in Table 2. Three hundred fifty-nine (51.3\%) of the 700 men had attended ANC with their partners, but most of them 685 (97.9\%) out of 700 provided financial support to their spouses to attend ANC. The majority of respondents 366 (52.3\%) out of 700 were not willing to use condoms during sexual intercourse for PMTCT of HIV.

3.3. Determinants of Male Involvement in the PMTCT Program. In order to measure the association of male involvement in PMTCT with a number of explanatory variables, crude and adjusted odds ratio (OR) with 95\% CI were employed and the result is given in Table 3. Compared to those who do not have education, those with education level of above grade $12(\mathrm{OR}(95 \% \mathrm{CI})=3.53(1.29,9.67))$ were more likely to be involved in PMTCT. Non-khat users (OR (95\%
CI $)=2.71(1.41,5.21)$ ) and nonsmokers $(\mathrm{OR}(95 \% \mathrm{CI})=7.29$ $(1.21,43.81))$ were more likely to be involved in PMTCT than their counterparts (Table 3 ).

\section{Discussion}

In this study, conducted to establish determinants of male involvement in the PMTCT program in southern Ethiopia, we found that $53 \%$ of male partners were involved in the PMTCT program. This level of involvement is higher than what is reported from other studies from East Africa [10]. One study in Kampala, Uganda, showed that male participation in the PMTCT activities was low (16\%) [11]. Similarly, a study conducted at a Nairobi antenatal clinic, Kenya, revealed that male partner participation in antenatal VCT with their spouses was low (15\%) [12]. This difference can be explained by the difference in background of the study participants 
TABLE 2: Level of involvement of the study participants in ANC activities in Arba Minch town and Zuria woreda, southern Ethiopia, 2014.

\begin{tabular}{|c|c|c|}
\hline \multirow{2}{*}{ Variables } & \multicolumn{2}{|c|}{ Respondent's response } \\
\hline & Yes: $n(\%)$ & No: $n(\%)$ \\
\hline Ever attended ANC with partner & $359(51.3)$ & $341(48.7)$ \\
\hline Knows partner's ANC appointments & $415(59.3)$ & $283(40.4)$ \\
\hline Provides financial support to partner to attend ANC & $685(97.9)$ & $15(2.1)$ \\
\hline Discusses with partner HIV testing & $409(58.4)$ & $291(41.6)$ \\
\hline $\begin{array}{l}\text { Do you accept if health professionals inform you to use condom during the } \\
\text { time of your wife's pregnancy }\end{array}$ & $334(47.7)$ & $366(52.3)$ \\
\hline Ever tested for HIV in ANC clinic & $375(53.6)$ & $325(46.4)$ \\
\hline Involved in PMTCT (having score of 4-6) & $371(53)$ & \\
\hline Not involved in MPTCT (having score of $0-3$ ) & $329(47)$ & \\
\hline
\end{tabular}

and the time gap as better attention has been given to male involvement in PMTCT these days.

In this study we have found a number of factors associated with male participation in the PMTCT program. These included age, residence, education level, knowledge on HIV, knowledge on PMTCT, geographical accessibility of health facility, having weak perception for male involvement in PMTCT, having perception of ANC attendance being females' responsibility, ever use of khat, and ever use of cigarette.

Male partners with comprehensive knowledge on HIV/AIDS were found to be 1.97 times more likely to be involved in the PMTCT program than those who do not have comprehensive knowledge on HIV/AIDS and this could be due to the fact that male partners who do not have comprehensive knowledge on HIV may fail to appreciate the importance of male involvement for prevention HIV infection from mother to child or may have less access to sexual and reproductive health education and promotion in general.

Regarding the association of education level with male involvement in PMTCT in this study, those who have education level of above grade 12 were almost four times more likely to be involved in PMTCT than those who do not have education level. This is in-line with the fact that people that are more knowledgeable could take care of HIV infection, as they easily understood both the transmission and prevention methods. Similar studies in Uganda and elsewhere have found that education level is an important determinant of participation in PMTCT services [11, 13].

In our study men who had knowledge about PMTCT program were almost 2 times more likely to get involved in PMTCT activities than those who had no knowledge. This is consistent with results of a similar study in Tanzania [2]. In addition, another study in Tanzania revealed that males were not fully participating in PMTCT programs and reasons given were lack of information and lack of a direct link between PMTCT staff and males [6].

Cultural factors were also found to be hindering male involvement in the PMTCT program in Arba Minch town and Zuria woreda. For example, antenatal care was perceived a women's affair and having weak perception for males who get involved in PMTCT. In this study compared to those who have weak perception for male involvement in PMTCT, those who do not were almost four times more likely to get involved in PMTCT and those who do not perceive antenatal care as women's affair were two times more likely to get involved in PMTCT than their counterparts. As has been shown in other studies it is conventional in many African cultures for men not to accompany their partners to antenatal and postnatal care consultations as pregnancy and child birth are regarded as women's affair [1].

Geographical accessibility of health facility (within $5 \mathrm{~km}$ distance) was positively associated with getting involved in the PMTCT program. The possible explanation for this association could be that the less a health facility is far away from the male partner's house the more a man comes in contact with the health facility with his partner and the more likely he is to get involved in PMTCT. Improving access to ANC is therefore a high priority for improving male involvement in PMTCT of HIV as shown in Thailand [14].

This study has also shown an association between age and male involvement in PMTCT in that those who are in the age range of 36-55 were almost two times more likely to get involved in PMTCT program than those who are 17-25 years old and this might be due to better understanding of older men on PMTCT than their counterparts.

\section{Limitations of the Study}

Being a cross-sectional survey, causality cannot be inferred from these findings and self-report might have also introduced social desirability bias. The data based on Selfdeclaration of men without women confirmation may limit our result on the evaluation of male involvement in PMTCT. Despite this limitation, the study provides useful information on perception of male partners for involvement of PMTCT that will inform health service planners to design a strategy to increase male involvement in PMTCT of HIV in Ethiopia. 
TABLE 3: Factors associated with male involvement in PMTCT of HIV among male partners (crude and adjusted OR) in Arba Minch town and Zuria woreda, southern Ethiopia, 2014.

\begin{tabular}{|c|c|c|c|c|c|}
\hline \multirow{2}{*}{ Explanatory variable } & \multicolumn{2}{|c|}{ Involved in PMTCT } & \multirow{2}{*}{ Crude OR $(95 \%$ CI $)$} & \multirow{2}{*}{ Adjusted OR (95\% CI) } & \multirow{2}{*}{$P$ value } \\
\hline & Yes (1) & No $(0)$ & & & \\
\hline Age & & & & & $<0.001$ \\
\hline $17-25$ & 79 & 89 & 1.00 & 1.00 & \\
\hline $26-35$ & 225 & 157 & $0.62(0.43,0.89)$ & $0.51(0.31,0.85)$ & \\
\hline $36-55$ & 67 & 83 & $1.10(0.71,1.71)$ & $2.07(1.13,3.81)$ & \\
\hline \multicolumn{6}{|l|}{ Residence } \\
\hline Rural & 168 & 75 & 1.00 & 1.00 & \\
\hline Urban & 203 & 254 & $2.80(2.02,3.90)$ & $2.05(1.31,3.22)$ & 0.002 \\
\hline Education level & & & & & 0.021 \\
\hline No education & 35 & 12 & 1.00 & 1.00 & \\
\hline Grades 1-4 & 39 & 34 & $2.54(1.14,5.66)$ & $1.10(0.39,3.12)$ & \\
\hline Grades 5-8 & 133 & 118 & $2.59(1.28,5.22)$ & $1.36(0.56,3.33)$ & \\
\hline Grades 9-12 & 137 & 75 & $1.60(0.78,3.26)$ & $1.25(0.50,3.10)$ & \\
\hline$>$ Grades 12 & 27 & 90 & $9.72(4.44,21.30)$ & $3.53(1.29,9.67)$ & \\
\hline \multicolumn{6}{|l|}{ Knowledge on HIV } \\
\hline Yes & 122 & 193 & $2.89(2.13,3.94)$ & $1.97(1.31,2.97)$ & 0.001 \\
\hline No & 249 & 136 & 1.00 & 1.00 & \\
\hline \multicolumn{6}{|l|}{ Knowledge on PMTCT } \\
\hline Yes & 97 & 156 & $2.55(1.86,3.50)$ & $2.18(1.39,3.41)$ & 0.001 \\
\hline No & 274 & 173 & 1.00 & 1.00 & \\
\hline \multicolumn{6}{|c|}{ Knowledge on ANC services } \\
\hline Yes & 45 & 238 & $18.83(12.69,27.94)$ & $5.73(3.64,9.02)$ & $<0.001$ \\
\hline No & 324 & 91 & 1.00 & 1.00 & \\
\hline \multicolumn{6}{|c|}{ Accessibility of health facility } \\
\hline Yes & 57 & 98 & $2.34(1.62,3.38)$ & $1.54(0.94,2.55)$ & 0.09 \\
\hline No & 314 & 231 & 1.00 & 1.00 & \\
\hline \multicolumn{6}{|c|}{ Weak perception for male involvement in PMTCT } \\
\hline Yes & 340 & 223 & 1.00 & 1.00 & \\
\hline No & 30 & 106 & $5.39(3.47,8.36)$ & $3.49(1.82,6.68)$ & $<0.001$ \\
\hline \multicolumn{6}{|c|}{ Attending ANC is females' responsibility } \\
\hline Yes & 323 & 179 & 1.00 & 1.00 & \\
\hline No & 48 & 150 & $5.64(3.88,8.19)$ & $1.96(1.11,3.45)$ & 0.02 \\
\hline \multicolumn{6}{|l|}{ Ever use of khat } \\
\hline Yes & 340 & 284 & 1.00 & 1.00 & \\
\hline No & 31 & 45 & $1.74(1.07,2.82)$ & $2.71(1.41,5.21)$ & 0.003 \\
\hline \multicolumn{6}{|l|}{ Ever use of cigarette } \\
\hline Yes & 369 & 312 & 1.00 & 1.00 & \\
\hline No & 2 & 17 & $10.05(2.30,43.85)$ & $7.29(1.21,43.81)$ & 0.03 \\
\hline
\end{tabular}

\section{Conclusion}

The level of male involvement in PMTCT program in Arba Minch town and Zuria woreda was 53\% in 2013. Several factors appear to contribute to male involvement in the PMTCT program including age, residence, education level, knowledge on HIV, knowledge on PMTCT, accessibility of health facility, having weak perception for male involvement in PMTCT, having perception of ANC attendance being females' responsibility, ever use of khat, and ever use of cigarette. Geographical accessibility of health facility and male's knowledge on PMTCT should be improved to increase their involvement in PMTCT.

\section{Conflict of Interests}

The authors declare that they have no competing interests.

\section{Authors' Contribution}

Marelign Tilahun was investigator and was involved in proposal writing, designing, recruitment and training of 
supervisors and data collectors, analysis and write-up, and all stages of the project implementation. He did most of the analysis and write-up of the paper. Shikur Mohamed contributed to the designing of the methodology, recruitment, and training of supervisors and data collectors and was involved in designing of project proposal, design of questionnaires, and supervision and was involved in the final approval of the paper. All authors read and approved the final paper.

\section{Acknowledgments}

The authors would like to acknowledge Arba Minch University for granting the fund to undertake this study. They are also thankful to the leaders of the districts where the study is conducted and male partners who participated in this study.

\section{References}

[1] F. Baiden, P. Remes, R. Baiden et al., "Voluntary counseling and HIV testing for pregnant women in the Kassena-Nankana district of northern Ghana: is couple counseling the way forward?" AIDS Care, vol. 17, no. 5, pp. 648-657, 2005.

[2] S. E. Msuya, E. Mbizvo, J. Uriyo, B. Stray-Pedersen, N. E. Sam, and A. Hussain, "Predictors of failure to return for HIV test results among pregnant women in Moshi, Tanzania," Journal of Acquired Immune Deficiency Syndromes, vol. 43, no. 1, pp. 8590, 2006

[3] H. Brou, G. Djohan, R. Becquet et al., "When do HIV-infected women disclose their HIV status to their male partner and why? A study in a PMTCT programme, Abidjan," PLoS Medicine, vol. 4, no. 12, article e342, 2007.

[4] C. Farquhar, J. N. Kiarie, B. A. Richardson et al., "Antenatal couple counseling increases uptake of interventions to prevent HIV-1 transmission," Journal of Acquired Immune Deficiency Syndromes, vol. 37, no. 5, pp. 1620-1626, 2004.

[5] F. Bajunirwe and M. Muzoora, "Barriers to the implementation of programs for the prevention of mother-to-child transmission of HIV: a cross-sectional survey in rural and urban Uganda," AIDS Research and Therapy, vol. 2, no. 1, article 10, 2005.

[6] S. E. Msuya, E. Mbizvo, A. Hussain, J. Uriyo, N. E. Sam, and B. Stray-Pedersen, "HIV among pregnant women in Moshi Tanzania: the role of sexual behavior, male partner characteristics and sexually transmitted infections," AIDS Research and Therapy, vol. 3, article 27, 2006.

[7] A. Medley, C. Garcia-Moreno, S. McGill, and S. Maman, "Rates, barriers and outcomes of HIV serostatus disclosure among women in developing countries: implications for prevention of mother-to-child transmission programmes," Bulletin of the World Health Organization, vol. 82, no. 4, pp. 299-307, 2004.

[8] J. Orne-Gliemann, P. T. Tchendjou, M. Miric et al., "Coupleoriented prenatal HIV counseling for HIV primary prevention: an acceptability study," BMC Public Health, vol. 10, article 197, 2010.

[9] T. S. Betancourt, E. J. Abrams, R. McBain, and M. C. S. Fawzi, "Family-centred approaches to the prevention of mother to child transmission of HIV," Journal of the International AIDS Society, vol. 13, no. 2, article S2, 2010.

[10] K. Semrau, L. Kuhn, C. Vwalika et al., "Women in couples antenatal HIV counseling and testing are not more likely to report adverse social events," AIDS, vol. 19, no. 6, pp. 603-609, 2005.

[11] M. Sarker, A. Sanou, R. Snow, J. Ganame, and A. Gondos, "Determinants of HIV counselling and testing participation in a prevention of mother-to-child transmission programme in rural Burkina Faso," Tropical Medicine and International Health, vol. 12, no. 12, pp. 1475-1483, 2007.

[12] R. Tweheyo, J. Konde-Lule, N. M. Tumwesigye, and J. N. Sekandi, "Male partner attendance of skilled antenatal care in peri-urban Gulu district, northern Uganda," Pregnancy and Child Birth, vol. 10, article 53, 2010.

[13] R. Byamugisha, J. K. Tumwine, N. Semiyaga, and T. Tylleskär, "Determinants of male involvement in the prevention of mother-to-child transmission of HIV programme in Eastern Uganda: a cross-sectional survey," Reproductive Health, vol. 7, no. 1 , article 12, 2010.

[14] A. Teeraratkul, R. J. Simonds, S. Asavapiriyanont et al., "Evaluating programs to prevent mother-to-child HIV transmission in two large Bangkok hospitals, 1999-2001," Journal of Acquired Immune Deficiency Syndromes, vol. 38, no. 2, pp. 208-212, 2005. 


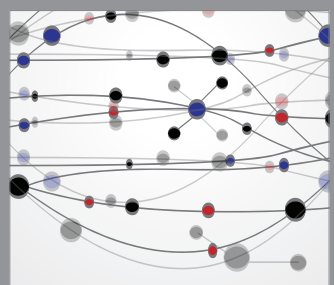

The Scientific World Journal
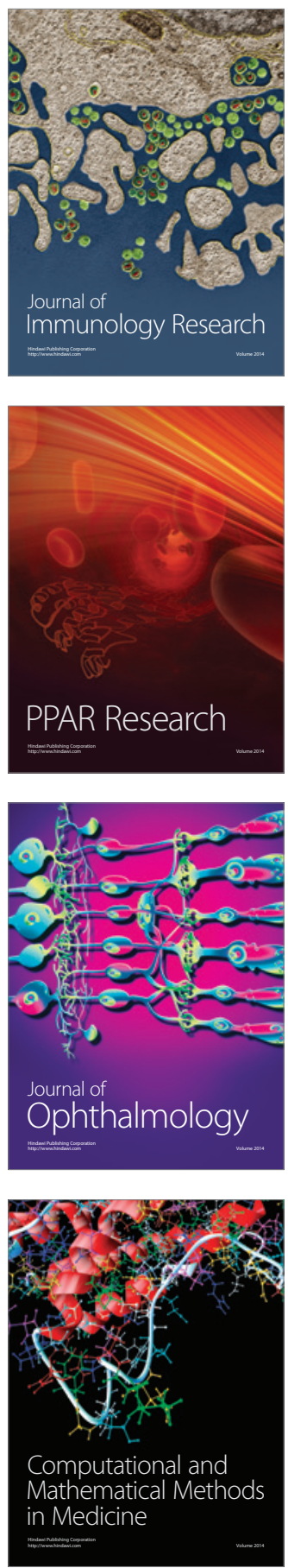

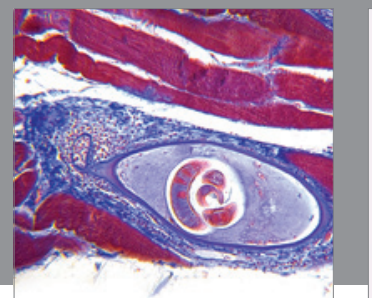

Gastroenterology

Research and Practice
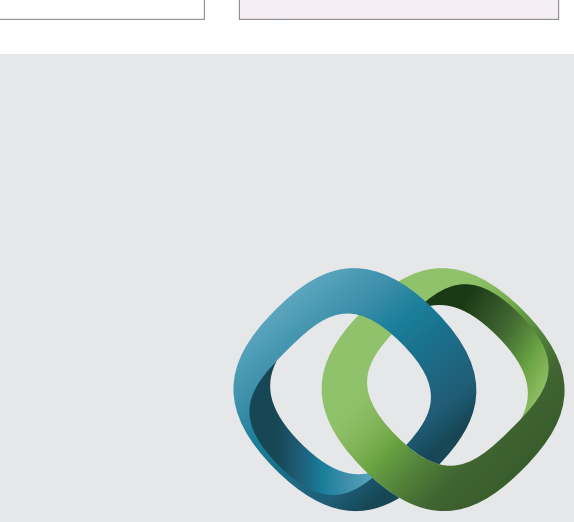

\section{Hindawi}

Submit your manuscripts at

http://www.hindawi.com
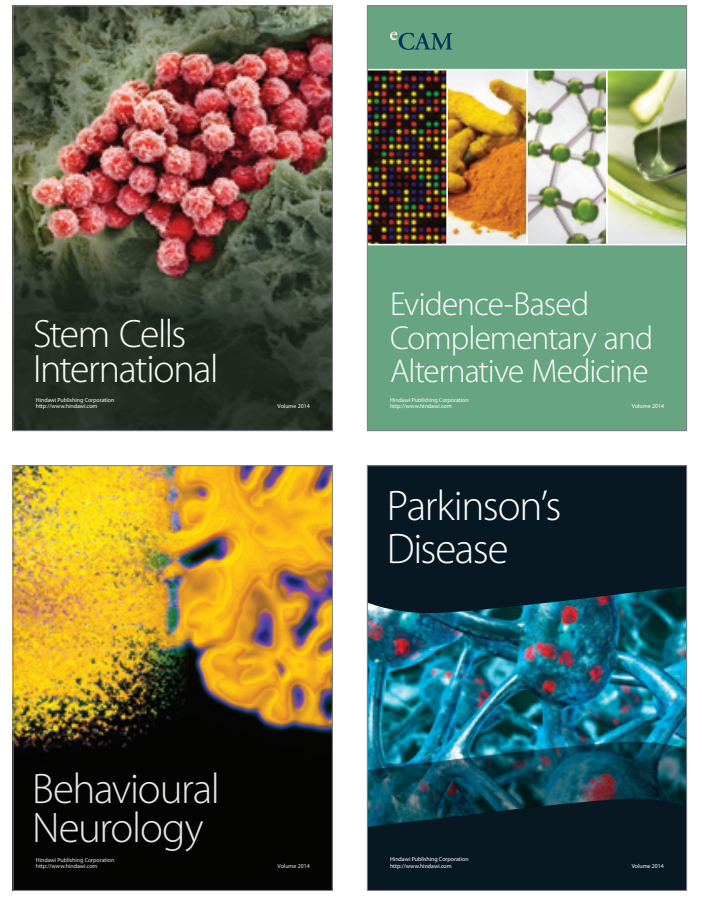
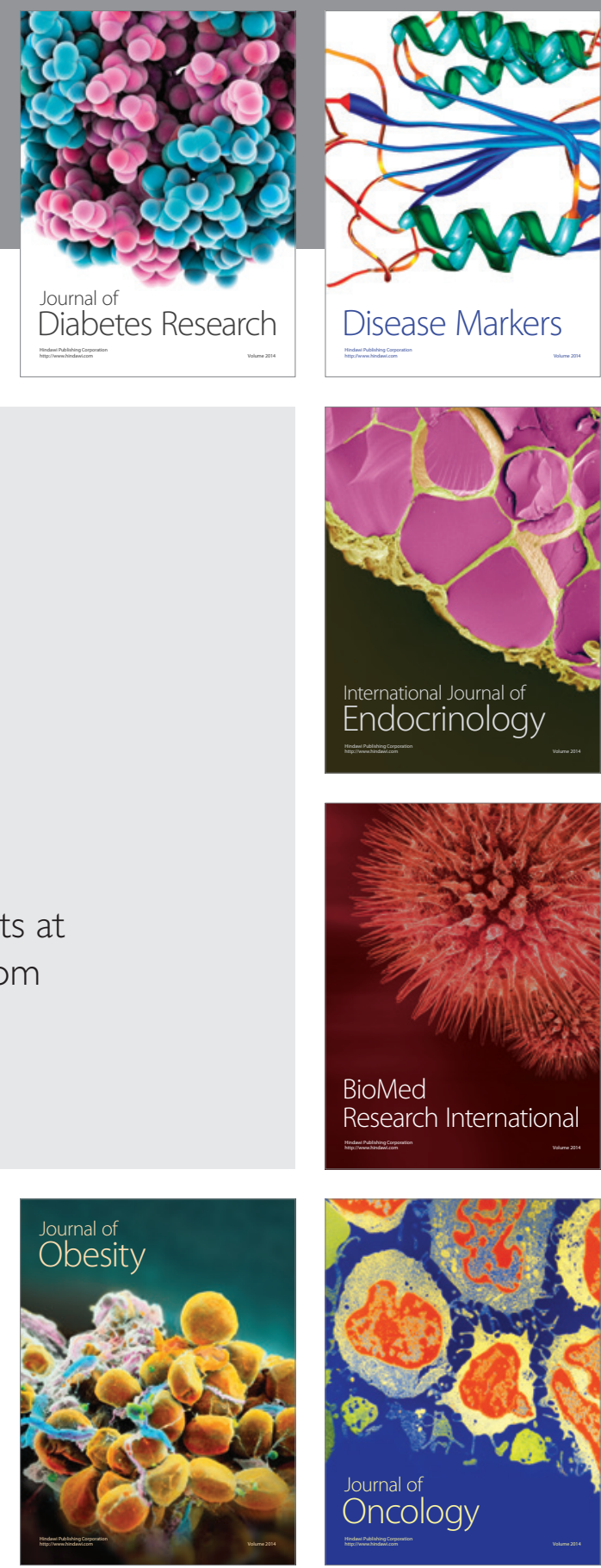

Disease Markers
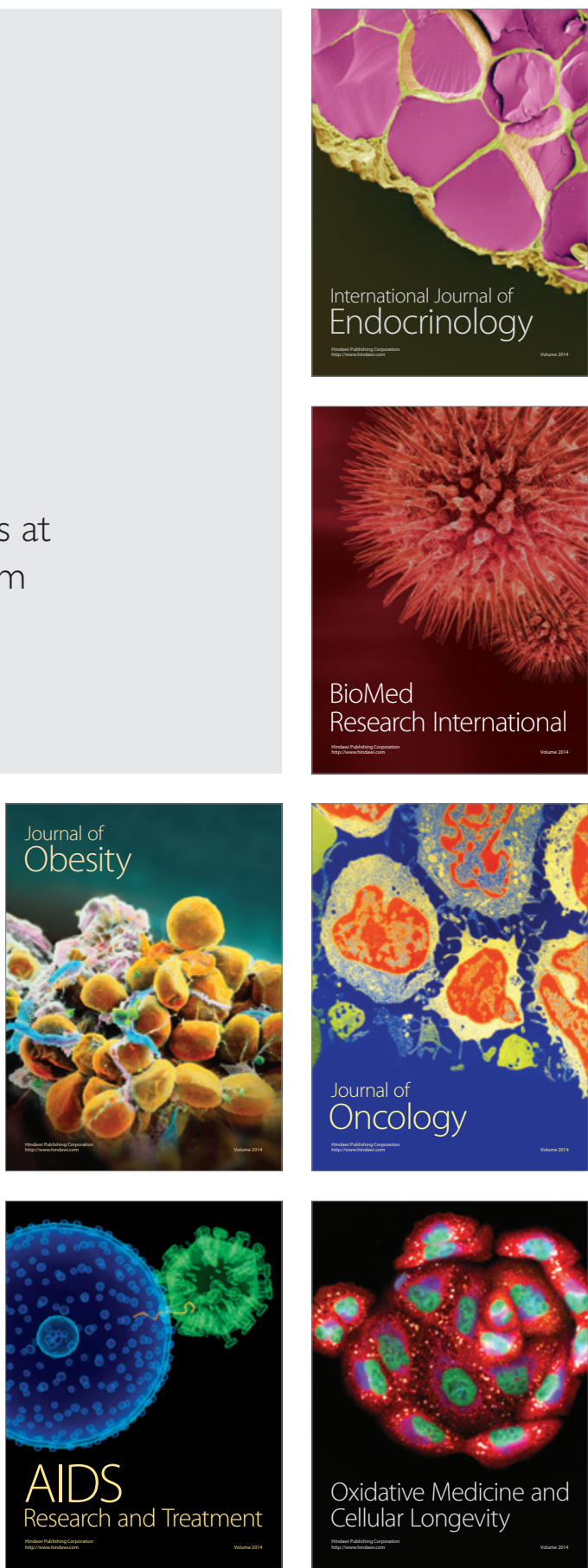